\title{
Bilim Dünyamızın Kanayan Yarasında Yeni İcatlar veya Adı Konulmamış Yayın Etiği ìhlalleri
}

\section{New Contrivancein the Bleaching Wound of Our Science World or Non-Named Publication Ethics Violations}

\section{Prof. Dr. M. Fatih KÖKSAL ${ }^{1}$}

Başvuru Tarihi: 31.12.2019

Kabul Tarihi: 05.03.2020

Makale Türü: Derleme

Öz

Etik değerler "erdemli insan" olma ülküsünün doğal ve beklenen bir sonucudur. Yayın etiği, bilimsel etĭgin, bilimsel etik de mesleki etĭgin bir parçasıdır. Mesleki etik, her meslek dalının kendine özgü, uzun bir zaman içinde oluşmuş, doğal ve beklenen davranış normları bütünüdür. Hangi meslek olursa olsun, mensuplarının insani, ahlaki ve vicdani bakımdan uymasi gereken ilkeler vardır. Bu ilkelerin, meslek mensubunun kendisine, meslektaşlarına, yaşadığı topluma ve nihayet topyekûn insanliğa yönelik sorumluluk kompartımanları vardır.

Bilimsel etik bilimsel araştırma yapan herkesin uyması ve benimsemesi gereken etik/ahlaki değerlerin genel adıdır. Bilimsel etĭ̆in en somut tezahürü, en önemli parçası ise yayın etiğidir. Yayın etiği, bilimsel çalışmalarda araştırmacının uyması gereken etik ilkeler bütünüdür. Yayın etiğine riayet bilim adamında bulunması gereken doğal bir davranış biçimi olmalıdır.

Ülkemizde yayın etiği ilkeleri, ilgili kurumlar tarafindan yasa, yönetmelik ve yönergeler çerçevesinde belirlenmiştir. Ne var ki uygulamada söz konusu yasa ve yönetmeliklerde tanımlanmamıs etik ihlallerin varlığı dikkatlerden kaçmamaktadır. Başka bir deyişle sahadaki uygulamalar, yeni yasal düzenlemelerin zorunlu olduğunu göstermektedir. Bu makalede adı konulmamış, tanımlanmamış yayın etiği ihlalleri ele alınmıştır.

Anahtar Kelimeler: Bilimsel Etik, Yayın Etiği, Bilimsel Araştırma

\section{Abstract}

Ethical values are a natural and expected result of the ideal of being a "virtuous person". Publication ethics is part of scientific ethics, and the scientific ethics is part of professional ethics. Professional ethics is the unity of natural and expected behavioral norms that are formed in a long

\footnotetext{
${ }^{1}$ İstanbul Kültür Üniversitesi Fen Edebiyat Fakültesi, mfkoksal@gmail.com, ORCID: 0000000310569957
} 
time and unique to each profession. Regardless of the profession, there are principles that its members must comply with in humane, moral and conscientious terms. These principles have responsibility compartments for himself, member of the profession, his colleagues, the community he lives in and finally the total humanity.

Scientific ethics is the general name of ethical/moral values that researchers conducting scientific research must comply with and adopt. The most concrete manifestation and the most important part of scientific ethics is publication ethics. Publication ethics is a collection of ethical principles that the researcher must follow in scientific studies. Compliance with publication ethics should be a natural form of behavior that should be found in the scientist.

However, in practice, the existence of ethical violations not defined in the related laws and regulations attracts attention. In other words, practices in the field show that new legal regulations are mandatory. This article deals with unnamed, unspecified publication ethics violations.

Keywords: Scientific Ethics, Publication Ethics, Scientific Research

\section{Giriş: Mesleki Etik < Bilimsel Etik < Yayın Etiği}

Bilimsel etiği en yalın hâliyle "bilim adamlarının bilimsel çalışmalarıyla ilgili hususlarda bilim adamında bulunması gereken dürüstlük, tarafsızlık, objektiflik gibi nitelikler çerçevesinde oluşmuş mesleki normlar bütünü” olarak tanımlayabiliriz. Bu normlara uymayan davranış kalıplarına ise "bilimsel etik ihlali" diyoruz. Yayın etiği ise bilimsel etiğin en önemli parçasıdır. Başka bir deyişle yayın etiği, bilimsel çalışmaların yayın boyutunu ilgilendiren davranış normlarıdır ve bilimsel etik ihlallerinin büyük çoğunluğu yayın etiği ile ilgili hususlardır. Bir de meslek etiği vardır ki, onu da herhangi bir meslek erbabının mesleğiyle ilgili tutum ve davranışlar manzumesi olarak tanımlamak mümkündür. Başka bir deyişle meslek etiğini akademisyenlik mesleği özelinde- hem yayın etiğini hem bilim etiğini içinde barındıran kapsayıcı şemsiye olarak düşünebiliriz. Şu hâlde bir akademisyenin mesleğiyle ilgili her türlü kural ve ahlak normları meslek etiğinin, sadece bilimsel çalışmalarla ilgili olanları bilimsel etiğin, bilimsel çalışmalarının yayınla ilgili olan tarafı da yayın etiğinin kapsamındadır. Bu farkı şöyle özetleyebiliriz. Bir öğretim elemanının derslerine zamanında girip çıkmaması, derslerde ders dışı konulardan bahsetmeyi alışkanlık hâline getirmesi, öğrencileriyle ilgilenmemesi, çalışma arkadaşlarına kaba davranması, ölçme ve değerlendirmede objektif olmaması vb. davranışlar mesleki etik ihlali kapsamındadır. Bilimsel araştırma için ayrılan kaynakların amacı dışında kullanılması, intihal yapması vb. davranışlar ise bilimsel etik ihlalidir. Bu, mesleki bir sorun da olduğundan mesleki etik ihlali de sayılır. Yazdığı bir makaleye başka bir çalışmadan bölümler aldığı veya başka bir çalışmadan yararlandığı hâlde yazarına atıf yapmaması ise yayın etiği; aynı zamanda hem bilimsel etik ihlali ve elbette "akademisyenlik mesleği” ile ilgili bir etik ihlal olduğu için aynı zamanda meslek etiği ihlali olmaktadır. 
Başta intihal olmak üzere bilimsel etik üzerine gerek yurt dışında gerekse ülkemizde yapılmış pek çok yayın vardır. Türkiye'de yapılan yayınların önemli kısmı çeviri kokmaktadır. Öyle ki, bunların çoğunda kimi yerlerde yazarın meramı dahi anlaşılamayacak derecede ifade kusurları mevcuttur. Bu yazıda herhangi bir yayın esas ve örnek olarak gözetilmemiş, yazarının akademik hayatında doğrudan tanık olduğu veya duyduğu olaylardan hareket edilmiştir. Yazıda tanımlanan ve tespit edebildiğimiz kadarıyla daha önce tanımı yapılmamış ve bir ad verilmemiş bu etik ihlallere, o tanıma en uygun isimler verilmeye çalışılmıştır.

$\mathrm{Bu}$ yazının amacı etik ihlallerin sebep veya sonuçlarını, bunları önlemenin yollarını tartışmak değildir. Bu hususta şu kadarını söylemekle yetineceğiz: Günümüzde gittikçe artan ve yeni yeni türleri ortaya çıkan etik ihlallerin -Türkiye özelinde- dört temel sebebi vardır. İlki, akademik hayatın esas amacının "bilim üretmek"ten çıkıp "unvan yükseltme”ye evirilmesi; buna paralel olarak yapılan yayınların içerik ve nitelikten ziyade biçim ve nicelik bakımından ölçümlenmesidir. İkincisi, sürekli artan üniversite sayısı dolayısıyla duyulan öğretim elemanı ihtiyacının normal şartların çok üstüne çıkmasının kalite beklentisini yahut bilimsel çıtayı aşağılara çekmesi, bunun da hâliyle düşük nitelikli bilim adamı yetişmesi sonucunu doğurmasıdır. Üçüncü bir sebep, her geçen gün gelişen iletişim teknolojisinin bilgiye erişimi inanılmaz derecede kolaylaştırırken birçok etik ihlali kolaylaştırıcı, çeşitlendirici hatta etik ihlale teşvik edici bir tarafının da bulunmasıdır. Nihayet dördüncü ve güncel bir sebep de son yıllarda bir yasa çerçevesinde uygulamaya konulan "akademik teşvik" uygulamasıdır. İyi niyetle hazırlanmış olmakla birlikte ülke gerçekleri, alanlara özgü durumlar, bilimsellik ölçütleri gibi temel esaslar yeterince gözetilmeden hazırlanan ve mütemadiyen değiştirilen bu yönetmelik, akademisyenlerin yayın performanslarını gerçekçi bir tarzda ölçüp değerlendirmekten çok onları ilgili yönetmelikte öngörüldüğü gibi yayın yapmaya sevk etmeye başlamıştır. Elbette sebepler sadece bunlar değildir. Bunların hepsi açılabilir, tartışılabilir, çözüm önerileri getirilebilir hususlardır. Fakat bunlar bu yazının kapsamı dâhilinde değildir. Bu yazıda, ülkemizde yükseköğretim işlerini yürütmekle yükümlü YÖK ve ÜAK ile TÜBİTAK, TÜBA gibi akademik kurumların ve üniversitelerin bilimsel etiğe dair yayımladıkları yönetmelik ve yönergelerde adı konmamış ve/veya tanımlanmamış ama çokça örneği görülen yayın etiği ihlalleri konu edilecektir. Söz konusu edilen etik ihlaller, "mesleki etik" normları çerçevesinde "birinci derece" ve "ikinci derece" olarak iki öbek altında değerlendirilmiştir.

\section{Birinci Derece Etik inlaller}

I.1. "Çift uçlu yayın”: Bu şekilde yapılan etik ihlal, mükerrer (tekrar) yayından farklıdır. Aşağıdaki tipleri tespit edilmiştir:

I.1.1. Bir kongrede bildiri olarak sunulan çalışmayı kongre bildiri metinleri arasında yayımlamadan türlü gerekçelerle başka bir yerde (makale, kitap bölümü vb. olarak) yayımlamak. Yayımlanmamış bir tebliğin sonradan makaleye dönüştürülmesinde hiçbir sakınca olmadığı gibi düzeltme, genişletme gibi zaruretler hasıl olduğunda gerekli bile sayılır. Ancak bu durumda bile, sempozyum veya kongre düzenleme kurulunun bildirilerin yayımlanamayacağına dair bir beyanı olmadan veya aradan uzun zaman geçmesine rağmen yayımlanmaması gibi bir durumla karşılaşılmaksızın yayımlanması etik değildir. Özellikle son 
zamanlarda kongrenin düzenlendiği yılın bitmesini bile beklemeden bildirinin makale olarak alelacele neşredilmesi, etik bir davranış olarak kabul edilemez. Zira sonradan o bildiri metni kongre kurulu tarafından yayımlandığında bir de mükerrer yayın problemi ortaya çıkacaktır. Dolayısıyla bildiri metni sempozyum kitabında yayımlanmadan önce "çift uçlu yayın", yayınlanırsa yönerge ve yönetmeliklerde zikredilen, tanımlı bir ihlal "tekrar yayın" (dublikasyon) olmaktadır. Bir tebliğ metninin kongre düzenleme kuruluna haber vermeksizin başka bir yerde yayımlanması da -ister "çift uçlu yayın" isterse "tekrar yayın" şeklinde olsunayrı bir etik sorunu oluşturur. Bir dergiye gönderilen makale nasıl dergi yönetiminden izin alınmaksızın orijinal diliyle veya yabancı dille veya başka bir yerde yayımlanamazsa tebliğ metni ile kongre düzenleme kurulu arasındaki ilişki de aynıdır.

$\mathrm{Bu}$ konuda altı çizilmesi gereken ikinci bir nokta da bir tebliğ sonradan makale olarak yayımlandığı takdirde, son şekil o olacağ 1 için doçentlik başvurularıyla akademik atama ve yükseltmelerde makale olarak neşredilenin esas yayın olarak sunulması, bildiri hâlinin hiçbir şekilde sunulmaması gerektiğidir. Yayımlanmış bir bildiri -açıklanabilir bir gerekçeyle- makale olarak yayımlandığı takdirde, başlığına düşülen bir dipnotla " $\mathrm{Bu}$ makale şu tarihte, şu sempozyumda sunulan bildiri metnidir / bildiri metninin genişletilmiş hâlidir.” vb. bir cümleyle durumu bildirmek zorunluluğu vardır. Ancak böyle bile olsa doçentlik başvurusu veya akademik atama ve yükseltmelerde her ikisinin de ayrı ayrı puanlandırılmaması gerekir. Bunun suç olduğu bilindiğinden, bu yayınlardan hangisi yazara puan bakımından avantaj sağlıyorsa o yayının sunulmasına tevessül edilmektedir ki, bu bilimsel açıdan da doğru ve uygun değildir. Konuyu biraz daha açacak olursak, adaya "akademik teşvik" uygulaması için bildiri yüksek puan getiriyorsa akademik teşvik için bildiriyi, doçentlik başvurusunda veya diğer atama ve yükseltmelerde makale yüksek puan getiriyorsa makaleyi kullanmak halk tabiriyle "sineğin yağını çıkarmak”tır ve bir etik ihlaldir. Gördüğümüz örnekler açısından daha somutlaştıralım: Akademik Teşvik Yönetmeliğìne göre -bunun nasıl bir anlayışla yapıldığı anlaşılmamakla birlikte- makale, kitap, derleme, kitap bölümü, editöre mektup, editörlük gibi pek çok akademik çalışma "Yayın” kategorisi üzerinden değerlendirilirken bilimsel toplantı yayınları "Tebliğ" kategorisinde ayrı bir faaliyet alanı olarak belirlenmiştir. Dolayısıyla -tam metin ve/veya özet metin" yayımlanan bir bildiri metninin akademik teşvik uygulamasında değeri makaleye göre yüksektir. Bize göre yayımlanmamış bir bildirinin dahi -gerekli şartlar oluşmadıkça- makale olarak yayımlanması etik ihlal oluştururken yayımlanmış bir bildiri metninin makale olarak yeniden yayımlaması YÖK ve ÜAK yönergelerine göre etik ihlal değildir; yeter ki akademik atama ve yükseltmelerde her ikisi birden kullanılmasın. ${ }^{2}$ Oysaki bunun apaçık tekrar yayın olduğu ortadadır. Bizim kanaatimiz, akademik başvurularda puanlansın veya puanlanmasın,

\footnotetext{
${ }^{2}$ Tekrar yayın yahut mükerrer yayın dediğimiz yayın etiği ihlali, Yükseköğretim Kurumları Bilimsel Araştırma ve Yayın Etiği Yönergesi’nin Madde 4 (1) ç) bendinde şöyle tanımlanmaktadır: “Tekrar yayım: Mükerrer yayınlarını akademik atama ve yükselmelerde ayrı yayınlar olarak sunmak". Bkz. https://www.yok.gov.tr/Sayfalar/Kurumsal/mevzuat/bilimsel-arastirma-ve-etik-yonetmeligi.aspx. Bu etik ihlalin tanımı, ÜAK Bilimsel Araştırma ve Yayın Etiği Yönergesi'nde madde, bende, etik ihlal adı ve tanım olarak kelimesi kelimesine aynıdır. Bkz. http://www.uak.gov.tr/yonetmelikler/Yay\%C4\%B1nEti\%C4\%9FiY\%C3\%B6nergesi_140318.pdf. Hâlbuki aynı etik ihlal, TÜBİTAK'ın Araştırma ve Yayın Etiği Kurulu Yönetmeliği'nin Madde-9 (g) bendinde de "Mükerrer yayım: Bir araştırmanın sonuçlarını, daha önce yayımlanma durumunu belirtmeden birden fazla kez yayımlamak veya yayımlamak için girişimde bulunmak” olarak tanımlanmıştır. https://ubimer.tubitak.gov.tr/sites/default/files/2017-09/AYEK\%20Yönetmeliği.pdf Arada çok ciddi bir fark vardır. YÖK ve ÜAK’a göre mükerrer yayın yapmak değil ancak "bu yayınları akademik atama ve yükseltmelerde ayrı ayrı yayınlar olarak sunmak" suç teşkil ederken TÜBİTAK değil yayını gerçekleştirmek, buna teşebbüs etmeyi dahi etik ihlal kabul etmektedir. Söz gelimi bir makalenin henüz yayımlanmadan hakem(ler) tarafından mükerrer yayın olduğunun tespiti dahi TÜBİTAK’a göre yayın etiği ihlalidir ki bizce de doğrusu budur.
} 
hatta sunulan bir bildiri yayımlanmamış dahi olsa aşağıdaki şartlar gerçekleşmedikçe böyle bir yayının etik olmadığı yönündedir:

a) Bildirinin sunulduğu kongre veya sempozyum düzenleme kurulunun bildirilerin yayımlanmayacağına dair kararının belgelendirilmesi,

b) Etkinliğin gerçekleştiği tarih üzerinden belli bir zaman aralığı (3 yıl makul bir süre olarak kabul edilebilir) geçmesi,

c) İlk iki seçenek gerçekleşmediği hâlde metin üzerinde kayda değer eklemeler, çıkarmalar, düzeltmeler vb. değişiklikler yapılması,

d) Yayının daha önce yapıldığı bilindiği hâlde diğer dergi/yayınevi/kurum yönetiminden gelen talep üzerine yayımlanması.

$\mathrm{Bu}$ şartların herhangi biri vaki olduğu takdirde, makale başlığına düşülecek bir dipnotla konunun açıklanması şartıyla bir bildiri makale olarak da yayımlanabilir.

I.1.2. Bir çalışmayı aynı anda birden fazla dergiye göndermek. Son zamanlarda özellikle Dergipark'ın kurulmasıyla akademik dergicilikte müthiş bir artışın olduğu gözlenmektedir. Bununla birlikte üniversiteler ve akademisyenlerin sayısı da artmıştır. Özellikle kimi üniversitelerin lisansüstü tezlerden yayın yapma mecburiyeti getirmesi yayın yapacak dergi arayışını üst noktaya taşımıştır. Hâliyle özellikle sınıflı dergilerde, Ulakbim TR Dizin'de ve ciddi uluslararası indekslerde taranan dergilerde yayın yapmak zorlaşmıştır. Bu durumda kimi akademisyenler yaptıkları çalışmayı bir an önce yayımlatmak için birden fazla dergiye göndermek gibi bir duruma tevessül etmektedirler. Söz konusu dergilerin editörlerinin yazıyı aynı hakeme göndermedikleri takdirde ortaya çıkması zor olan bu etik ihlali yapanlar, derginin birinden yayım kararı çıkınca diğerine yazıyı çekmek istediklerine dair bilgi notu göndermekte, böylece çalışmanın iki yerde birden yayımlanmasının önüne geçmektedirler. Bu aynı zamanda "sahtecilik" de içeren ciddi bir etik ihlaldir.

I.1.3. Bir dergiye yayımlanmak üzere gönderilen bir çalışmayı, hakem düzeltmeleri ve önerileri geldikten sonra -dergi yönetimine bildirerek veya bildirmeksizin- o dergiden çekerek yahut dergi yönetimine herhangi bir açıklama yapmaksızın başka bir dergide yayımlamak da sık karşılaşılan durumlardandır. Böyle bir yaklaşımdan yazarın amacının ne olabileceğine dair farklı değerlendirmeler yapılabilirse de akademisyende olması gereken temel değerlerden “dürüstlük”le bu tavrın örtüşmeyeceği aşikârdır. Zira bu durumda yazar, önceki derginin hakemlerinden veya editöründen ciddi destek ve katkılar aldığı hâlde bütün bunlar hiç olmamış gibi başka bir dergiye kusur ve eksiklikleri en aza indirgenmiş ve büyük ihtimalle doğrudan kabul edilecek bir yazı göndererek yazı üzerinde emeği bulunanların emeklerini ret ve inkâr edilmiş olmaktadır ki bir tür emek hırsızlığıdır ve elbette bilimsel yayın etiğiyle bağdaşmayan bir davranıştır.

I.2. “Görevi kötüye kullanma:” TÜBİTAK Yönetmeliğinde "Görevi ihmal etme veya kötüye kullanma" şeklinde ifadesini bulan bu etik ihlalini "kötüye kullanma" ve "ihmal" olarak iki farklı kategoride değerlendirmek daha doğru olacaktır. ÜAK Yönetmeliğinde yer almayan bu ihlal 
türü TUBİTAK Yayın Etiği Kurulu Yönetmeliği'nde şsöyle tanımlanmıştır: "Kurumun iş ve değerlendirme süreçlerinde yer alan hakem, danışman, uzman, editör, panelist, moderatör, izleyici, raportör, komite veya kurul üyeliği ve benzeri görevleri yerine getirirken usulüne uygun davranmamak, görevi ihmal etmek veya kötüye kullanmak”. Bu etik ihlali, ilk bakışta kuruma özgü bir konu gibi görünse de akademik hayatın bütününe teşmil edilebilecek nitelikte, önemli bir problemdir. Konunun "ihmal" kısmını "ikinci derece etik ihlalleri" bahsinde değerlendirmek üzere daha vahim olan "kötüye kullanma" ihlalini değerlendirelim. Bu ihlalin farklı uygulamaları vardır:

1.2.1. "Sızdırma": Bilimsel yayınlarla ilgili her tür yazışma gizli kalmalı, dışarıya sızdırılmamalıdır. Kör hakemlik uygulayan dergi/yayınevi/kurum editörlerinin hakem veya raportör isimlerini yazara yahut yazar adını hakem veya raportöre bildirmeleri önemli bir etik ihlaldir ve bu kapsamda değerlendirilmelidir.

I.2.2. "Yanlı davranma": Dergilerde, bilimsel kurum ve etkinliklerde editör, düzenleyici vb. yönetim kademesindeki kimselerin kendilerine yayımlanmak/sunulmak üzere gönderilen kitap, makale, bildiri, proje vb. çalışmaları hakemlere gönderirken yazı sahibinin kimliğine göre tercihte bulunmak; hakemlik ve yayın sürecini haksız olarak geciktirmek veya öne almak. Bu da eşitlik, dürüstlük, adalet gibi bilim adamlığının temel hasletlerine taban tabana zit bir davranıştır.

1.2.3. "Haksız müdahale": Editörlüğü, redaktörlüğü veya hakemliği yapılan dergi, kitap, kongre veya armağan kitabı vb. yayınlarda, makale/bildiri sahibinin izni, bilgisi ve haberi olmadan yazısından bir bölüm çıkarmak veya yazısına bölüm eklemek. Bir kongreye sunulan bildirileri düzenlemek veya redakte etmekle görevli bir kurul üyesinin gönderilen bildirilerden birine, bildiri sahibinin bilgisi olmaksızın kendine veya bir başkasına ait bir çalışmadan bölüm(ler) eklemesi, böylece kendisine veya bir yakınına bir atıf icat etmesi bu duruma tipik bir örnektir. Bir bildiri, kitapta bölüm veya makaleden bir bölümün veya atfın, kaynakçadan bir kaynağın editör tarafından her ne sebeple olursa olsun çıkarılması da aynı şekilde bir etik ihlaldir.

I.3. “Örtülï dublikasyon”: Bir yayında ortaya konan tezlerin başka yayın(lar)da, yayının kayda değer bir kısmını kaplayacak şekilde lafzı farklılaştırılarak tekrar edilmesi. Bu durumda yazarın, söz konusu yayına atıf yapması ve makalenin özünün farklı bir tezi savunuyor olması hâlinde etik ihlal kabul edilemez. Ancak bilim adamının eski yayın veya yayınlarına atıf yapmadan ${ }^{4}$ veya daha çok alıntı yaptığı veya yararlandığı hâlde bunların yalnızca bir kısmına atıf yapması bir etik ihlaldir. Bu, tekrar yayından ve dilimlemeden farklı ama her ikisinden de izler taşıyan, en az onlar kadar önemli bir etik ihlaldir.

\footnotetext{
${ }^{3}$ https://tubimer.tubitak.gov.tr/sites/default/files/2017-09/AYEK\%20Yönetmeliği.pdf

${ }^{4}$ Bütün uluslararası bilimsel etik ilkelerinde etik ihlal olarak kabul edilen, TÜBİTAK’ın Araştırma ve Yayın Etiği Kurulu Yönetmeliği’nin Madde-9 (g) bendinde de "Yayımlanmış veya yayına sunulmuş kendi çalışmasından usulüne uygun olarak kaynak göstermeden alıntı yapmak" şeklinde açıklanan "kendinden intihal” olarak tanımlayabileceğimiz etik ihlali YÖK’ün Yükseköğretim Kurulları Bilimsel Araştırma ve Yayın Etiği Kurulu ve ÜAK’ın Bilimsel Araştırma ve Yayım Etiği Yönergesi’nde tanımlanmamıştır.
} 
I.4. "Haksız atıf": Yayında, aslında çalışmayla doğrudan ilgisi bulunmayan eserlere atıfta bulunmak veya ilgisiz yayınlara kaynakçada yer vermek. "Çoğunlukla "akademik yükselme" kaygısıyla ilgili alanın doçent ve daha çok da profesörlerinin yayınlarına bu tür "hediye atıf"larda bulunulduğu görülmektedir. Kimi yakınlık ilişkileri de hediye atıf gerekçesi olabilmektedir. Etik yönetmelik ve yönergelerinin "haksız yazarlık" tanımında etik görülmeyen "yazar üretme" ile bizim "haksız atıf" olarak tanımladığımız "atıf üretme" arasında bilimsel yayın etiği bakımından hiçbir fark yoktur.

I.5. "Görmezden/bilmezden gelme": Araştırma konusuyla ilgili daha önce yapılmış yayınlardan haberi yokmuş gibi davranarak yayınını -açıç̧a veya zımnen- o konuda yapılmış ilk yayın veya özgün bir çalışma gibi göstermek. Yazar o konuda daha önce yapılan çalışmalardan gerçekten haberdar değilse, literatür taramasını yeterince yap(a)madığı için metodik kusur ve eksikliği var demektir ve etik ihlal sayılmaz. Ancak yazarın bu çalışma(lar)dan haberdar olduğunun bir şekilde tespiti hâlinde açık bir etik ihlal kabul edilmelidir.

\section{İkinci Derece Etik ihlaller}

II.1. "Kongre avcılığı": Bu etik ihlalin farklı uygulamaları vardır. Bir bilimsel toplantıya katılacağını bildirdiği (bildiri başlığı, özet vs. gönderilip) hâlde mazeret bildirmeksizin katılmamak ve/veya katılıp bildirisini sunduğu hâlde bildiri metnini göndermemek bunlardan biridir. Bilimsel toplantılarda bildiri sunmanın bir dergide makale yayımlamaktan farkı bildirisini, konuyla ilgili bir topluluğun huzurunda sunmak, dinleyicilerin varsa eleştiri, katkı, ekleme ve düzeltmelerini anında almak, tartışılabilir bir ortam içinde tezini savunmaktadır. Hâl böyle olunca, katılmadığı bir toplantıya gönderilen bildirinin makaleden farkı kalmaz. Ayrıca toplantılara mazeretsiz katılmamak, akademisyenliğin gerektirdiği ciddiyet ve güvenilirlik gibi nitelikleri de zedeler mahiyette bir davranış olduğu gibi organizasyonun aksamasına da yol açar. Bu devamsızlığı âdet hâline getiren akademisyenler vardır. Aynı şekilde toplantıya katılıp bildiri de sunulduğu hâlde şu veya bu sebeple bildiri tam metnini zamanında göndermemek de bildiri kitabının basımının gecikmesinin yanı sıra yazarın akademik yetkinliği, ciddiyetine gölge düşürecek bir davranış biçimidir. Bildirisindeki görüş ve tespitlerin arkasında duramadığı izlenimi de doğuracak böyle bir davranış da etik kabul edilemez. Maalesef akademik hayatımızda son zamanlarda aynı gün aynı saate iki farklı şehirde yapılan kongre programında bildiri sunduğu görülen akademisyenlere de tanık olunmaktadır. Kongre avcılığının bir başka türü de adına "tebliğ" ya da "bildiri” denemeyecek sunumlarla bilimsel toplantılara iştirak etmektir. Özellikle kongre giderlerinin üniversite veya düzenleyici kurum -devlet kurumları, belediyeler, vakıflar vb. kuruluşlar- tarafından karşılandığı "kongre bahane, gezi şahane" toplantıları da ancak "kongre avcılı̆̆ı" adıyla tanımlanabilir. Bu cümleden olarak gayrı ciddi bildirileri sözde bilim kurulu marifetiyle kabul eden -bunların özellikle bu işi ticarete dönüştüren kişi ve kuruluşlarca yapıldığı düşünüldügünde "kongre bahane, gelir şahane" diyen- düzenleme kurulları, bilim kurulları ve hakemler de bu ihlale teselsülen katılmış olurlar. ${ }^{5}$

\footnotetext{
${ }^{5}$ Doğrudan bu yazının konusu olmamakla birlikte özellikle akademik teşvik uygulamasından sonra yenilenen her yönetmeliğe göre kendisini yenileyen organizasyonlarla yapılan "yağmacı kongreler” bilim dünyamızın çok önemli bir problemi olduğunun altını çizmeliyiz. Bazılarına devlet kurumlarının da alet edildiği, burada ayrıntısına girmek istemediğimiz pek çok çirkinliği barındıran, tamamen maddi çıkar amacıyla yapılan bu "organize kongreler"e katılımın akademik yükselmelerde kullanılmasının ilgili kurumlar tarafından yapılacak sıkı denetimlerle önüne geçilmesi elzemdir.
} 
II. 2. "Hatada 1srar": Çok karşılaşılan bir sorun olmamakla birlikte bu da bir etik problemdir. Bir yayın hakkında, o çalışmada açıklanan hususların, ulaşılan sonuçların veya tezlerin yanlışlığının somut delillerle ortaya konduğu başka yayın(lar) yapıldığında, yazar(lar)dan yapılan eleştirilere cevap mahiyetinde bir yayın yapılmadığı takdirde eleştirilen hususların yazar(lar)ca kabullenildiği anlamı çıkar. Söz konusu yayın bir kitapsa ve kitabın yeniden basımı söz konusu ise yeni basımda bu hatalar düzeltilmelidir. Hem yapılan eleştirilere karşı yayınını savunmamak hem de aynı hataları tekrarlamak bir anlamda okuru ve bilim dünyasını yanıltmak olacağından bu davranış da bir tür etik ihlaldir.

II.3. “Görevi ihmal etme:” "Görevi kötüye kullanma veya ihmal etme” şeklinde yer aldığı hâlde TÜBİTAK Yönetmeliğinde yer alan ama ÜAK Yönetmeliğinde bulunmayan bir etik ihlalden yukarıda bahsetmiştik. "Kötüye kullanma" kadar açı bir ihlal olmasa da "görevi ihmal etme" de kabul edilebilir bir davranış değildir. Dergilere gönderilen makalelerde, çeşitli kurumlara veya yayınevlerine gönderilen kitaplarda, kongre ve sempozyumlara gönderilen/sunulan bildirilerde, projelerde ve her türlü yayın faaliyetinde editörlük, hakemlik, raportörlük, oturum başkanlığı, akademik kurullarda üyelik ve türlü karar mekanizmaları, akademik anlamda hayati önemi haizdir. Bir dergiye gönderilen makale hakkında makaleyi etraflıca incelemeden, üzerine notlar düşüp varsa yazarın hatalarını belirtmeden, öneriler getirmeden ve sağlıklı, açık ve anlaşılabilir değerlendirmelerde bulunmadan "kabul" veya "red" kararı vermek yazarın gelişimine hiçbir katkı sağlamayacaktır ve akademik etikle bağdaşmayan bir davranıştır. Her nasıl olursa olsun, kararın gerekçesini yazarın sebebini bilme hakkı vardır. Hakem, editör vb. görevde olanların bu görevlerini objektif kriterlere uygun ve tarafsız ve âdil olarak yürütmeleri ve süresi içinde sonuçlandırmaları gerekir. $\mathrm{Bu}$ görevleri kabul edip zamanında sonuçlandırmamak, hiç ilgilenmemek veya yanlı karar vermek de etik olarak kabul edilemez ve bunlar da etik ihlaldir. Yine uhdesine verilen raportörlük, hakemlik, jüri üyeliği vb. bilimsel danışmanlık görevini, belirlenen süre içinde sonuçlandırmamak da etik bir davranış değildir ve mutlaka bir müeyyidesi olmalıdır.

II.4. "Paralı yayın: Son zamanların en önde gelen etik problemidir. Bunu kitap ve makale neşri olarak iki kısımda değerlendirmek gerekir. Üniversiteler, çeşitli bakanlıklar, Türk Tarih Kurumu, Türk Dil Kurumu, Türkiye Yazmalar Kurumu, TÜBA vb. resmî kurumlar dişında yayımlanan akademik kitapların yayın sürecinde -editörlük, hakemlik, raportörlük gibi- ciddi bilimsel filtrelerden geçmeksizin yayımlandıkları gözlenmektedir. Özellikle doçentlik başvurusunda "basılı kitap"ın zorunlu tutulmasından sonra ${ }^{6}$ birçok yayınevi, kendilerine gelen dosyanın bilimsel değeriyle ilgilenmeden -ki zaten çoğunun böyle bir kadrosu yoktur- belli bir ücret mukabilinde basmaktadırlar. Bu belki tek başına etik sorun gibi görünmeyebilir ancak bir anlamda hakemsiz dergide makale yayımlatmak gibi olduğundan bilimsel zafiyet taşıdı̆̆ aşikârdır.

\footnotetext{
${ }^{6}$ Eskiden doçentlik başvurularında basılmamış, tez gibi fotokopi usulüyle çoğaltılarak ciltlenmiş çalışmalar da kitap olarak kabul edilirdi ve aslında bu daha doğruydu. Zira böylece sunulan basılmamıș kitapta jüri üyelerince tespit edilen muhtemel bazı hataların düzeltilmesi, eksikliklerin tamamlanması imkânı vardı. ÜAK’ın bu usule yeniden dönmesinde bu bakımdan fayda bulunduğu gibi basılı kitap şartının kaldırılması doçent adaylarını fırsatçı yayınevlerinin tasallutundan da kurtaracaktır.
} 
Bu sorunun ikinci ayağı dergilerdir. Bir bilimsel dergi, herhangi bir resmî kurum, vakıf, dernek vb. kuruluştan destek almadan sadece kendi imkânlarıyla yayın hayatını sürdürüyorsa ve basılı dergiyse yazarlardan baskı masraflarını ve hakemlere ödeme yapıyorsa hakem ücretlerini karşılamak üzere belli bir miktarda ücret talep etmesi makul görünmektedir. Keza bazen elektronik dergilerde DOI numarası almak, web hizmetleri sunmak, server kiralama, tasarım yaptırma durumlarına karşı cüzi para alabilmektedirler ki bu da anlaşılır. Ancak bunların hiçbiri söz konusu olmadığı hâlde acıtıcı miktarda para talep etmek uygun değildir. Bu durum ilk bakışta ticari bir mesele gibi görünebilir ancak bilimsel gelişmeye sekte vurması açısından bilimsel etikle, söz konusu olan şey "yayın” olduğuna göre yayın etiği ile ilgilidir. Neredeyse ayda bir sayı neşreden ve her sayısında yüzlerce makaleye yer veren bu dergiler, belirtilen meblağı yatıran hemen herkesin makalesini içeriği ne olursa olsun yayınlamaktadır ki konunun etik boyutu buradadır. Nitekim bazı üniversitelerimiz tarafından yayımlanan "yağmacı dergiler listesi” bu tiksinti verici durumu önlemek amacıyla uygulamaya sokulmuştur. Ancak bu dergilerde yayım yapmakla ilgili bir müeyyide de yoktur.

Aynı durum "sözde uluslararası" kongreler için de söz konusudur. "Disiplinlerarası" kisvesi altında merdiven altı kongreler türemiş, benzeşmeyen bilim dallarından yüzlerce kişinin katılımıyla gerçekte yapılıp yapılmadığı bile belli olmayan sempozyumlar, sunulup sunulmadı̆̆ bilinmeyen bildiriler ortaya çıkmıştır ve bu üzücü manzara akademik dünyamızı kirlettikçe kirletmektedir. Gerek dergi gerekse sempozyum-kongre boyutunda olsun, bu tür organizasyonlarda hem düzenleyici/editör hem de katılımcı/yazar olarak yer almak kuşkusuz şık değildir. Özellikle mesleğin başlangıcında bilmeyerek bu tür dergilerde yayın yapan veya bu tür kongrelere heves eden genç akademisyenlerin böylesi suçlamalara maruz kalmamak için dergi ve etkinlik seçiminde dikkatli ve özenli olmaları gerekir.

II.5. “Muğlak yazarlık”: Çok yazarlı bir yayında kimin eserin hangi kısmına ne tür katkıda bulunduğunun açıkça belirtilmemesi. Söz gelimi sosyal bilimler alanında hazırlanmış bir kitap çalışmasında dört yazarın adı olduğu hâlde kimin hangi bölümü hazırladığı ve/veya görev paylaşımında katkısının ne olduğunun belirtilmesi yazarların emeklerine saygının bir gereği olduğu gibi haksız yazarlık gibi birinci dereceden etik ihlal sayılan bir olumsuz algıyı da önleyecektir.

\section{Sonuç}

YÖK’ün önemli bir tedbir olarak lisansüstü eğitimde "Bilimsel Araştırma Yöntemleri ve Yayın Etiği” dersini bütün bölümlerde okutulacak zorunlu ders olarak müfredata aldırması önemli bir adımdır ancak yeterli değildir. Bu dersin, neredeyse farklı dersler işleniyor intibaını uyandıracak kadar farklı uygulamalar, farklı yaklaşımlarla işlendiğini biliyor, görüyoruz. Ülkemizde henüz içselleştirilemeyen bilimsel etik duyarlılı̆̆ı, tabandan tavana yayılacak bir tarzda ilkokuldan itibaren ele alınması gereken toplumsal ahlak meselesidir aynı zamanda. Bilimsel etik konusunu içselleştiremeyişimize tipik ve güncel bir örnek olarak YÖK’ün her yıl Akademik Teşvik Yönetmeliği’nde değişikliklere gitmesini gösterebiliriz. Bu değişikliklere duyulan ihtiyacın bir gerekçesi tasarruf tedbirleri çerçevesinde düşünülebilirse de kayda değer bir sebebinin de "etik" olduğuna kuşku yoktur. Burada ifade edilen ve edilemeyen ihlallerin önlenmesine dair de 
elbette söylenecek çok şey vardır. Çok önemsediğimiz bir çözüm yolunu ifade etmekle yetinelim: Artık akademik yayınların adedine ve sayısal puanlamalarına dayalı olarak değerlendirildiği anlayıştan içerik değerine, önemine ve alanına sağladığı katkıya bakıldığı yeni bir anlayışa geçilmelidir.

Dileğimiz, başta YÖK ve ÜAK yönergeleri olmak üzere, Türk yüksek öğretimiyle ilgili bütün kurumların burada zikredilen ihlalleri yasal çerçevede değerlendirmeye almaları ve bilimsel etik ihlallerinin her türlüsünün üzerine ciddiyetle ve kararlılıkla gitmeleridir.

\section{Kaynakça}

https://www.yok.gov.tr/Sayfalar/Kurumsal/mevzuat/bilimsel-arastirma-ve-etik-

yonetmeligi.aspx (E.T.: 20.09.2019)

http://www.uak.gov.tr/yonetmelikler/Yay\%C4\%B1nEti\%C4\%9FiY\%C3\%B6nergesi_140318.p

df (E.T.: 20.09.2019)

https://tubimer.tubitak.gov.tr/sites/default/files/2017-09/AYEK\%20Yönetmeliği.pdf

(E.T.:

24.11.2020) 